\title{
Generate a Meta-Model Content for Collaboration Space of Learning Management System Compatible with IMS-LD
}

\author{
https://doi.org/10.3991/ijim.v13i01.9440 \\ Mohammed Ouadoud ${ }^{(\varpi)}$ \\ Abdelmalek Essaadi University, Tetouan, Morocco \\ mohammed. ouadoud@gmail. com \\ Tarik Chafiq \\ University Hassan II, Casablanca, Morocco \\ Nouha Rida \\ Mohammed V University, Rabat, Morocco \\ Mohamed Yassin Chkouri \\ Abdelmalek Essaadi University, Tetouan, Morocco
}

\begin{abstract}
The context of this work is that of designing an IMS-LD ${ }^{1}$ model for collaboration space of a $\mathrm{LMS}^{2}$. Our work is specifically in the field or seeking to promote, by means of information technology from a distance. Our approach is to first think about the conditions for creating a real collaboration space between learners, and designing the IT environment that supports this space. In this paper, we try to adapt the IMS-LD model with a collaboration model for Learning Management System based on the social constructivism. This adaptation will go through three stages. Firstly, the development of an LMS model. Secondly, the study of correspondence between the developed model and IMS-LD model. Finally their transformation to IMS-LD model.
\end{abstract}

Keywords - LMS, collaboration space, IMS-LD, eLearning platform, designing an IMS-LD meta-model

\section{Introduction}

E-Learning is promoted through educational platforms: integrated systems offer a wide range of activities in the learning process. Teachers use the platforms to monitor or evaluate the work of students. They use LMS to create courses, tests, etc. However, the LMS eLearning platforms do not offer personalized services and therefore do not take into account the aspects of personalization such as the level of knowledge, interest, motivation and goals of learners. They access the same resource sets in the same way.

${ }^{1}$ IMS-LD: Instructional Management Systems - Learning Design

${ }^{2}$ LMS: Learning Management System 
In fact, we present an easy collaboration meta-model of LMS to create and administer the educational content online. This tool allows the generation and editing structures of websites through database rather than pedagogical models, with a variety of choices that ensures better adaptation to the teaching of the course and learning style. Therefore, it is necessary to find a method to model all LMS types. In order to modeling the collaboration space of LMS we have based ourselves upon the IMS-LD specification focusing on learning theory that was judged the most important and relevant to our modeling, namely the social constructivism. Then, this learning theory which have inspired for a long time the design of computer applications are combined and put into perspective with several emergent pedagogical functionalities to build an original modeling for our collaboration space of LMS. This reveals that this proposed modeling that is presented to readers here looks for ways to leverage technology for learning by considering users as being human actors and not human factors [12].

The IMS-LD specification or instructional design engineering uses pedagogical concepts, allowing to model learning units. IMS-LD takes into account a wide variety of teaching models it is there its flexibility. A course plan extract of a general or specific database can be modeled with IMS-LD, through the description of the different roles, activities, environments, methods ${ }^{3}$, properties, conditions and notifications. It is used to transform the course plans into formal learning units (UOL) that can be performed with an IMS-LD editor based on an engine such as Coppercore [18]. These executable units can be designed from the beginning using an editor such as Reload [19].

During the last decade, the LMS eLearning platforms have evolved considerably. However, several modeling of LMS platforms have been developed previously [13], [14], [15], [16], [17], but they have been abandoned because platforms' life cycle is changing apace. Therefore, we have conducted a comparative and analytic study on free e-learning platforms based on an approach of evaluating the e-learning platforms quality [1], [2], [3], [26]. Based on these various research works, which seemed to us incomplete, we proposed a modeling portrait of a designing an IMS-LD collaboration model for LMS platform. This latter relies on a learning conception that is located at the intersection of the most used learning theory.

To concretize our modeling work, we present in the section "Theoretical approach, concepts and related work" the different theories of learning used for the modeling of this space, namely the social constructivism. We also present the e-learning specification IMS-LD and related work. Next, in "transformation rules" section, we present the ATL transformation language to perform the transformation between the developed meta-model and IMS-LD model. We also determine in this section, the reasons why, we did not use the ATL language for transformation of models. Thereafter, we present in the section "Model-driven engineering", the modeling Driven Architecture (MDA). Thus, we try to adapt the proposed meta-model of the collaboration space to the equivalent IMS-LD model. Finally, in "designing a collaboration meta-model based on IMS-LD" section, we present our proposition of the conceptual meta-model of the collaboration space.

\footnotetext{
${ }^{3}$ The word "method" used by IMS-LD means the unfolding of the scenario.
} 


\section{$2 \quad$ LMS Activity Spaces}

The learning management system consists of different activity spaces for activities of teaching and learning [11], [9], [27]. Each model represents a space, in these spaces, both teachers and learners can have:

- In disciplinary information space, teachers or tutors can export content from the LMS as IMS/SCORM conformant Content Packages that can be viewed offline, or imported into the LMS. Entire courses or individual course units can be packaged for viewing or redistribution.

- Communication is the act of conveying intended meanings from one entity or group to another using mutually understood signs and semiotic rules. Learners can communicate with others through their Inbox using LMS's private mail, through the discussion forums or the chat rooms.

- Collaboration is the process of two or more people or organizations working together to realize or achieve something successfully [29]. Collaboration requires leadership, although the form of leadership can be social within a decentralized and egalitarian group [28]. Teams that work collaboratively can obtain greater resources, recognition and reward when facing competition for finite resources.

- Sharing space or exchange space, it allows discussing, to define and to follow the implementation of collaborative projects of one or several courses.

- Evaluation is a process where learners are assessed to determine their suitability to take a course. The learners' aptitudes are determined by a variety of techniques including interviews, group exercises, presentations, examinations and psychometric testing.

- In production space, the teacher or tutor can create notifications, and assess the productions undertaken by learners.

- Self-management is the management of an LMS by the administrators themselves. The customizations are decentralized as much as possible and the sharing of tasks between all the users (administrators, coordinators, teachers, tutors, and learners) is done equitably.

- Assistance designates the action of bringing help or relief. It is about providing aid, support or relief in all matters.

\section{Theoretical Approach, Concepts and Related Work}

\subsection{LMS and the social constructivism}

The social constructivism is the fruit of the development of learning theories under the influence of some researchers, particularly Lev Vygotski in 1934 [24], [25], who wanted to depart from the behaviorism by integrating other factors that are able to positively influencing the knowledge acquisition. Thus, new ideas emerged in connection with the possible interaction of individuals with the environment. 
The social constructivism outlines learning by construction in a community of learners. In this light, learners are expected to interact with the available human resources (teachers, tutors, other learners...) in the proposed learning environment. In this way, the learners' psychological functions increase through socio-cognitive conflicts that occur between them. These conflicts lead to the development of the zone of proximal development4 [8] and thus facilitate the acquisition of knowledge.

Learning is seen as the process of acquisition of knowledge through the exchange between teachers and learners or between learners. These latter learn not only through the transmission of knowledge by their teacher but also through interactions [10]. According to this model, learning is a matter of the development of the zone of proximal development: this zone includes the tasks that learners can achieve under the guidance of an adult; they are not very tough or so easy. The development of this zone is a sign that the learners' level of potential development increases efficiently [30].

The teacher's role is to define precisely this zone in order to design suitable exercises for learners. Furthermore, designing collaborative tasks, which involve discussions and exchange (socio-cognitive conflicts) between learners is so important in this model. Errors are considered as a point of support for the construction of new knowledge.

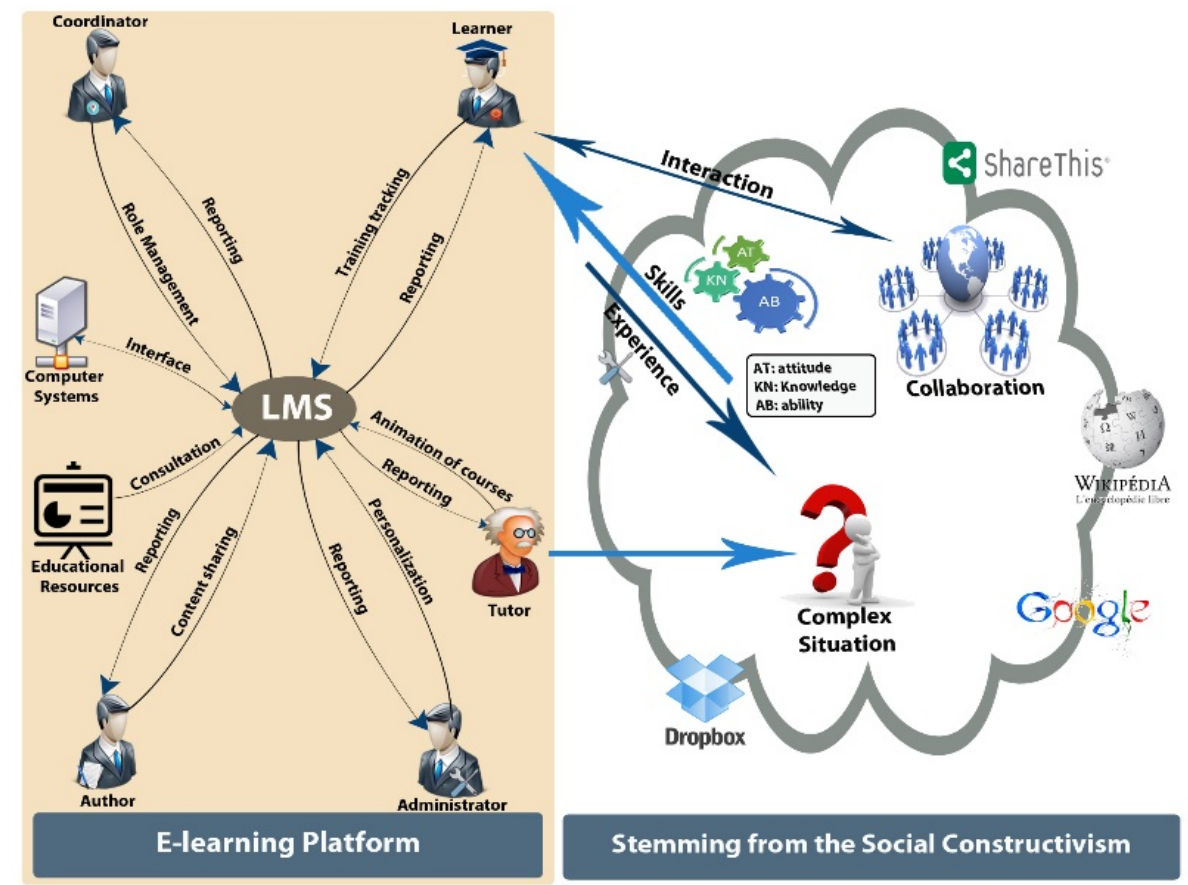

Fig. 1. LMS and underlying Social Constructivism model

\footnotetext{
4 "The distance between actual development level as determined by independent problem solving and the level of potential development as determined through problem solving under adult guidance or in collaboration with more capable peers (Vygotsky, 1978, p. 86)".
} 
Based on the social constructivism approach (cf. Figure 1), the design of LMS were oriented towards integrating online communication and collaboration tools. In practice, a wide range of platforms, particularly the social constructivist ones, propose a set of tools, which allow sharing, exchanging and interacting in synchronous and asynchronous mode such as blogs, wikis, forums...

In summary, the ideas of social constructivist authors have highlighted the social nature of learning. Other authors have taken one-step further by emphasizing the distribution of intelligence between individuals and the environment. Furthermore, considering that learning occur in a social context is no longer enough to ensure deep learning. Indeed, working in groups can affect negatively the quality of learning if these following conditions are not taken into consideration: Learning styles, the way groups are formed, interaction modality, and the characteristics of tasks.

\subsection{Instructional Management Systems - Learning Design}

There are several eLearning specifications, for example: $\mathrm{SCORM}^{5}$, DCMI ${ }^{6}$, IMS$\mathrm{SS}^{7}$ or IMS-CP ${ }^{8}$. Among these, IMS-LD, one of the last publications, seeks to incorporate pedagogical flexibility and complements certain aspects treated by others.

IMS-LD was published in 2003 by the IMS/GLC. (Instructional Management Systems Global Learning Consortium: Consortium for global learning management systems with training, the original name when IMS was started in 1997 Instructional Management Systems project) [4], [7]. Reminds us of its origins: the source $\left(\mathrm{EML}^{9}\right)$ of the proposed language was assessed by the European Committee for Standardization (CEN) in a comparative study of different SRMS [5], [7], as best suited to satisfy the criteria definition of an EML. EML is defined by CEN / ISS as "an information aggregation and semantic model describing the content and processes involved in a unit of learning from an educational perspective and in order to ensure the reusability and interoperability." [7], [23] In this context, the North American IMS consortium undertook a study and provided a specification of such a language, giving birth in February 2003, the Learning Design specification V1.0 (IMS-LD). She adds that proposal, largely inspired EML developed by [6], [7] (OUNL) provides a conceptual framework for modeling a Learning Unit and claims to offer a good compromise between on the one hand to the generic implement a variety of instructional approaches and secondly, the power of expression that allows an accurate description of each learning unit.

This specification allows us to represent and encode learning structures for learners both alone and in groups, compiled by roles, such as "learners" and "Team" (cf. Figure 2) [7]. We can model a lesson plan in IMS-LD, defining roles, learning activities,

\footnotetext{
${ }^{5}$ SCORM: Sharable Content Object Reference Model. Available at https://www.adlnet.gov/adlresearch/scorm/

${ }^{6}$ DCMI: Dublin Core Metadata Initiative. Available at http://dublincore.org/.

${ }^{7}$ IMS-SS: Instructional Management Systems - Simple Sequencing. Available at https://www.imsglobal.org/simplesequencing

${ }^{8}$ IMS-CP: Instructional Management Systems-Content Packaging. Available at https://www.imsglobal.org/content/packaging

${ }^{9}$ EML: Educational Modelling Language.
} 
services and many other elements and building learning units. The syllabus is modeled and built with resources assembled in a compressed Zip file then started by an executable ("player"). It coordinates the teachers, students and activities as long as the respective learning process progresses. A user takes a "role" to play and execute the activities related to in order to achieve a satisfactory learning unit. In all, the unit structure, roles and activities build the learning scenario to be executed in a system compatible with IMS-LD.

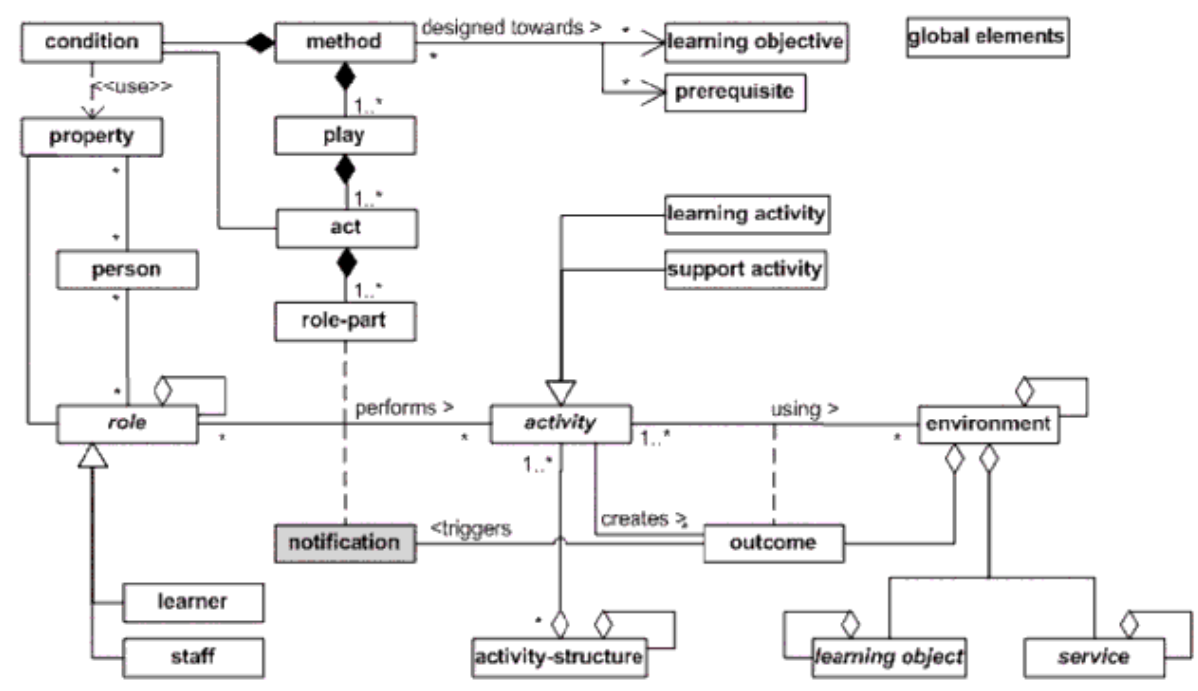

Fig. 2. The conceptual model of Instructional Management Systems - Learning Design [7]

IMS-LD does not impose a particular pedagogical model but can be used with a large number of scenarios and pedagogic models, demonstrating its flexibility. Therefore, IMS-LD is often called a meta-pedagogic model. Previous eLearning initiatives claim to be pedagogically neutral, IMS-LS is not intended to pedagogical neutrality but seeks to raise awareness of eLearning on the need for a flexible approach.

IMS-LD has been developed for E-Learning and virtual classes, but a course face to face can be done and integrated into a structure created with this specification, as an activity of learning or support activity. If the ultimate goal to create rich learning units, with support to achieve the learning objectives by providing the best possible experience, face-to-face meetings, and any other learning resource are permitted such as video conferencing, collaborative table or any field action research.

IMS-LD uses the theatrical metaphor, which implies the existence of roles, resources and learning scenario itself: one room is divided into one or more acts and conducted by several actors who can take on different roles at different times. Each role is to carry out a number of activities to complete the learning process. In addition, all roles must be synchronized at the end of each act before processing the next act. 


\subsection{Related works}

A great deal of research is focusing in one way or another on the platforms engineering for distance education, including LMS. For example Chekour [24], presented a synthesis of the main learning theories in the digital era, namely: the behaviorism, the cognitivism, the constructivism and the social constructivism. El-Mhouti [25] highlighted the ICT use in the service of active pedagogies, based on the social constructivist approach, the principles that structure the instructional design approaches, and the assessment of the social constructivist activities.

These works, among many others, emphasized the contribution of learning theories in the design and development of learning systems. The direct application of each of these theories allows particularly providing supporting methods to the design and development of LMS. The learning theory that we presented in this paper as an original conceptual model has allowed us to design a new LMS whose benefit resides essentially in the richness of the proposed functionalities in a way that fits the needs of all its final users: teachers and learners.

Furthermore, much work has been done in the field of collaborative learning and IMS-LD specification. For example, Dyke [21] explains how models socio-cognitive interaction are related to the properties of collaborative tools. Ferraris [22] expresses collaborative learning scenarios by teachers animating virtual classrooms to promote the re-use and share teaching practices. He proposes an approach led by the models in accordance with the recommendations of the Model Driven Architecture OMG. He presents a meta-model based on IMS-LD enhanced by the concepts of participation model to capture the richness of the interactions inherent in collaborative activities. Moreover, El-Moudden [20], [23] proposes a designing an IMS-LD model for collaborative learning. His approach is to first think about the conditions for creating a real collective activity between learners, and designing the IT environment that supports these activities.

On the other hand, other research aimed at proposing the modeling of new units, approach, architecture, or adaptive, flexible and interactive eLearning devices. For example, Sadiq proposed the modeling of learning units on eLearning platforms, which relies on the application of the standard IMS-LD in the production of adaptive learning units [13].

Based on these various research works, which seemed to us incomplete, we proposed a modeling portrait of a designing an IMS-LD collaboration Model for LMS platform. For us, this is not the same case and the same vision as our modelization is more general, it aims on one hand to create a LMS from which teachers can animate virtual groups for the re-use and sharing of teaching practices and on the other hand, the re-use of the content created in other frameworks. Indeed, the idea is to orient the design work research towards a great and optimal compatibility between the services offered by E-Learning platforms (LMS) and the needs of all users, particularly learners, for better optimization of online learning. 


\section{Transformation Rules}

\subsection{Atlas Language Transformation (ATL)}

In their operational ATL, Canals et al use. [35], [20] State that to deal with the transformation of models; it is difficult and cumbersome to use object languages since we spend so much effort to the development of transformation definitions of Framework for the set work. The use of XSLT as a language if it is more direct and adapted by rest against difficult to maintain [35], [20]. We follow their choice by focusing on the implementation of approaches centered on the MDA (Model Driven Architecture), MDE (Model Driven Engineering) and QVT (Queries View Transformation) tools. Query / View / Transformation (QVT) [37], [20] is a standard defined by the OMG. This is a standardized language to express model transformations. QVT is not advanced sufficiently now in its definition for Queries and View aspects. Against transformation by the appearance expressed by MDA, approach has resulted in various experiments (eg Triskell, ATL) in both academic and commercial level. To determine the transformation, it is necessary to have tools of transformations. These are based on languages transformations must respect the QVT standard [37], [20] proposed by the OMG [36], [20]. There is an offer of free tools (ATL, MTF, MTL, QVTP, etc.) and commercial (eg MIA). We chose ATL (Atlas Transformation Language) from the provision of free tools, to the extent that only ATL has a spirit consistent with OMG / MDA / MOF / QVT [35], [20].

\subsection{ATL Description}

Atlas Transformation Language (ATL) has been designed to perform transformations within the MDA Framework proposed by the OMG [38], [39], [20]. The ATL language is mainly because the models are first-class entities. Indeed, the transformations are considered models of Transformation. Since transformations are considered themselves as models, we can apply their transformations. This possibility of ATL is considered an important point. Indeed, it provides the means to achieve higher order transformations (HOT Higher- Order Processing) [39], [20]. A higher-order transformation is a transformation including source and target models that are themselves transformations. As ATL is among the languages model transformation respecting the QVT [37] standard proposed by OMG [36], we describe its structure in relation to this standard (QVT).

The study of the abstract syntax of the ATL language is to study two features provided by this language more than rules changes. The first feature, navigation, allows studying the possibility of navigation between meta-models sources and targets. The second feature, Operations, used to describe the ability to define operations on model elements. Finally, the study of the transformation rules is used to describe these types of rules, how they are called and the type of results they return.

- Navigation [38], [36], [20] this feature is offered by ATL language (Object Constraint Language). Navigation is allowed only if the model elements are fully ini- 
tialized. The elements of the target model cannot be definitively initialized at the end of the execution of the transformation. Therefore, the navigation in ATL can only be made between elements of the model (or meta-model) source and model (or meta-model) target.

- Operations: [38], [20] this feature ATL is also provided by the OCL (Object Constraint Language). In OCL, operations can be defined on the elements of the model. ATL takes this opportunity to OCL to allow defining operations on elements of the source model and the transformation model [36], [20].

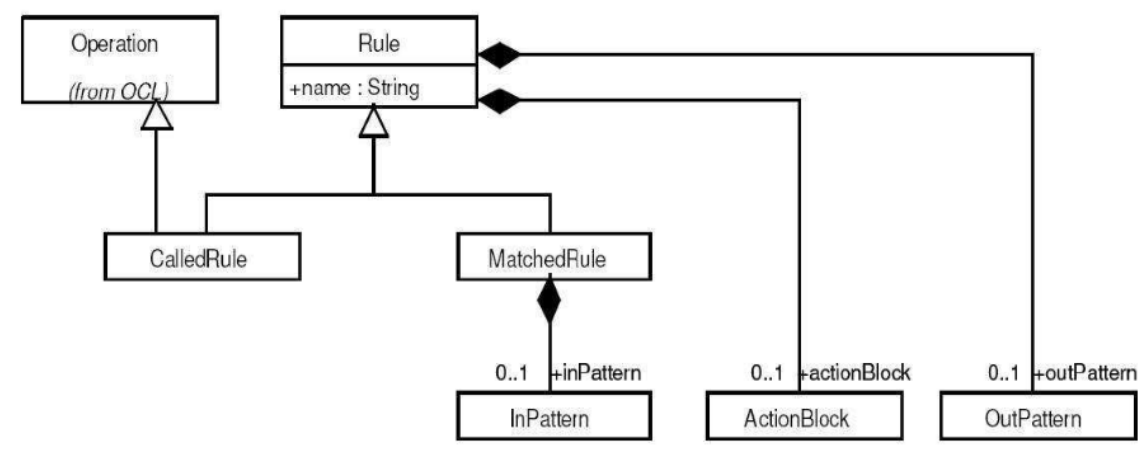

Fig. 3. ATL Transformation rules [20]

The transformation rules: there are several types of transformation rules based on how they are called and what kind of results they return (cf. figure 3 ).

CalledRule [38] rule explicitly called by its name and by setting its parameters.

MatchedRule [38] rule executed when a guy (InPattern) scheme is recognized in the source model.

The result of a rule may be a set of predefined models (OutPattern) or a block of mandatory (ActionBlock). If the rule is MatchedRule type and if its result is a set of elements of the target model (OutPattern), it was named declarative. If it is CalledRule type whose result is a block of statements, it is then called procedure. Combinations of rules (declarative and imperative) are called hybrid rules [36].

\subsection{Synthesis}

In this research, we try to adapt the model IMS-LD with a collaborative metamodel supporting LMS. This adaptation will go through three stages, first the development of a collaborative meta-model; secondly, the study of correspondence between the developed meta-model and IMS-LD model and their transformation to IMS-LD meta-model that reduced the MDA approach in a transformation that is based on the rules implemented in the ATL language. However, we will talk about the IT design of our LMS collaborative meta-model without using the transformation that is based on the rules implemented in the ATL language, because we have detected the same problems as in several works [20], [23], [40], [41], [42]. In IMS-LD, we do not have the opportunity to build a Project, which consists of several Projects. For this, 
there is at this level a semantic loss. Frankly, we find that there are the real problems of semantic loss during the transformation of our collaborative meta-model to an IMS-LD meta-model with the ATL language.Model-Driven Engineering

\subsection{Modeling Driven Architecture (MDA)}

In November 2000, the OMG in the field of software engineering consortium of over 1,000 companies, has initiated the process MDA [OMG MDA], the conceptsoriented models rather than object-oriented. The Model Driven Architecture MDA [OMG MDA] offers the power of abstraction, refinement and different views of the models. This standard has to add a new way to design applications by separating business logic from business, any technical platform to increase the reuse of previously developed code, reducing development time and facilitating the integration of new technology [31]. It gives the opportunity to develop independent models platforms and implementation [32] environment. MDA is used to separate two extreme views of the same system [33]:

- Its functional specifications on the one hand.

- Its physical implementation on the other hand.

Including several aspects of the life of the software, namely its tests, its quality requirements, the definition of successive iterations, etc. The MDA architecture consists of four layers. In the center, there is a UML (Unified Modeling Language) standard MOF (Meta-Object Facility) and CWM (Common Warehouse Meta-model). The second layer contains the XMI (XML Metadata Interchange) standard for dialogue between the middleware (Java, CORBA, .NET, and Web services). The next layer refers to the services to manage events, transaction security, and directories. The last layer offers specific frameworks in scope (Telecommunications, medicine, electronic commerce, finance, etc.) A designer to create his own application can use UML as it can use other languages. So according to this architecture independent technical context, MDA proposes to structure the front needs to engage in a transformation of this functional modeling technical modeling while testing each product model [33]. This application model is to be created independently of the target implementation (hardware or software). This allows greater reuse of patterns. MDA is considered an approach with the ambition to offer the widest possible view of the life cycle of the software, not content with only its production. Moreover, this is intended overview described in a unified syntax. One of the assumptions underlying the MDA is that the operationalization of an abstract model is not a trivial problem. One of the benefits of MDA is to solve this problem [34]. MDA proposes to design an application through software chain is divided into four phases with the aim of flexible implementation, integration, maintenance and test:

- The development of a computer model without concern (CIM: Computer Independent Model).

- The manual transformation into a model in a particular technological context (PIM: Platform Independent Model). 
- The automatic transformation into a pattern associated with the target implementation of the platform (PSM: Platform Specific Model) model to be refined,

- Its implementation in the target platform.

\subsection{Correspondence between the terminology of IMS-LD and that of the LMS collaboration meta-model}

The majority of classes designed in our collaboration meta-model correspond perfectly with the IMS-LD model, which makes possible their transformation to it. The transformation of model is a technique aims to put links between models in order to avoid unnecessary reproductions.

In the table I, we have tried to collect all classes of the collaboration meta-model and their equivalent at the IMS-LD.

Table 1. Correspondence between the terminology of IMS-LD and that of the collaboration meta-model of LMS

\begin{tabular}{|l|l|}
\multicolumn{2}{|c|}{ Collaboration meta-model } \\
\hline Project & Activity \\
\hline Task, and subtask & Activity structure \\
\hline Phase & Play \\
\hline Role, and features & Role \\
\hline Members, and team & Person \\
\hline Coordinator, teacher, and tutor & Staff \\
\hline Learner & Learner \\
\hline Collaboration space & Environment \\
\hline Objective & Learning Objective \\
\hline Course & Learning Object \\
\hline Tools & Services \\
\hline
\end{tabular}

\section{Designing a Collaboration Meta-Model based on IMS-LD}

In our research, we propose meta-model for a system designed to achieve the needs of LMS platform, and the needs of teachers and learners. Therefore, we establish the following diagram as a first proposal of collaboration meta-model for LMS platform.

Indeed, we will talk about the IT design of our collaboration meta-model for LMS. This led us to develop our meta-model in which we will eventually identify the features of the constituent entities of our meta-model in which we specify the different classes of our modeling.

Teachers, tutors, and learners can promote collaboration experiences through the meta-model tools presented in figure 4 and these following technological advances:

- Forum. Teachers, tutors, or learners can create and manage multiple forums for each of their courses. Messages can be edited, deleted, locked from reading and/or replying, and "stuck" if a message is important. Administrators or coordinators can create forums shared across multiple courses. 
- Glossary. Words and phrases added to the glossary by the teacher, the tutors, or the learner, can be accessed from terms embedded within content pages, or viewed alphabetically in their entirety using the glossary tool.

- Blog. Provide collaborative blogging and/or online journaling capability for your course or project team.

- Wiki is a module that provides collaborative modification of its content and structure. The key intention of this wiki is to provide a simple collaborative teaching tool suitable for learners use.

- Portfolio. This module allows learners to create portfolio contributions, with a structure set by the teacher. The course teacher(s) can create an overall structure for the learners' work via a series of chapters. The course learners are then able to add their own contributions based on this structure, which can then be commented by the course teacher(s).

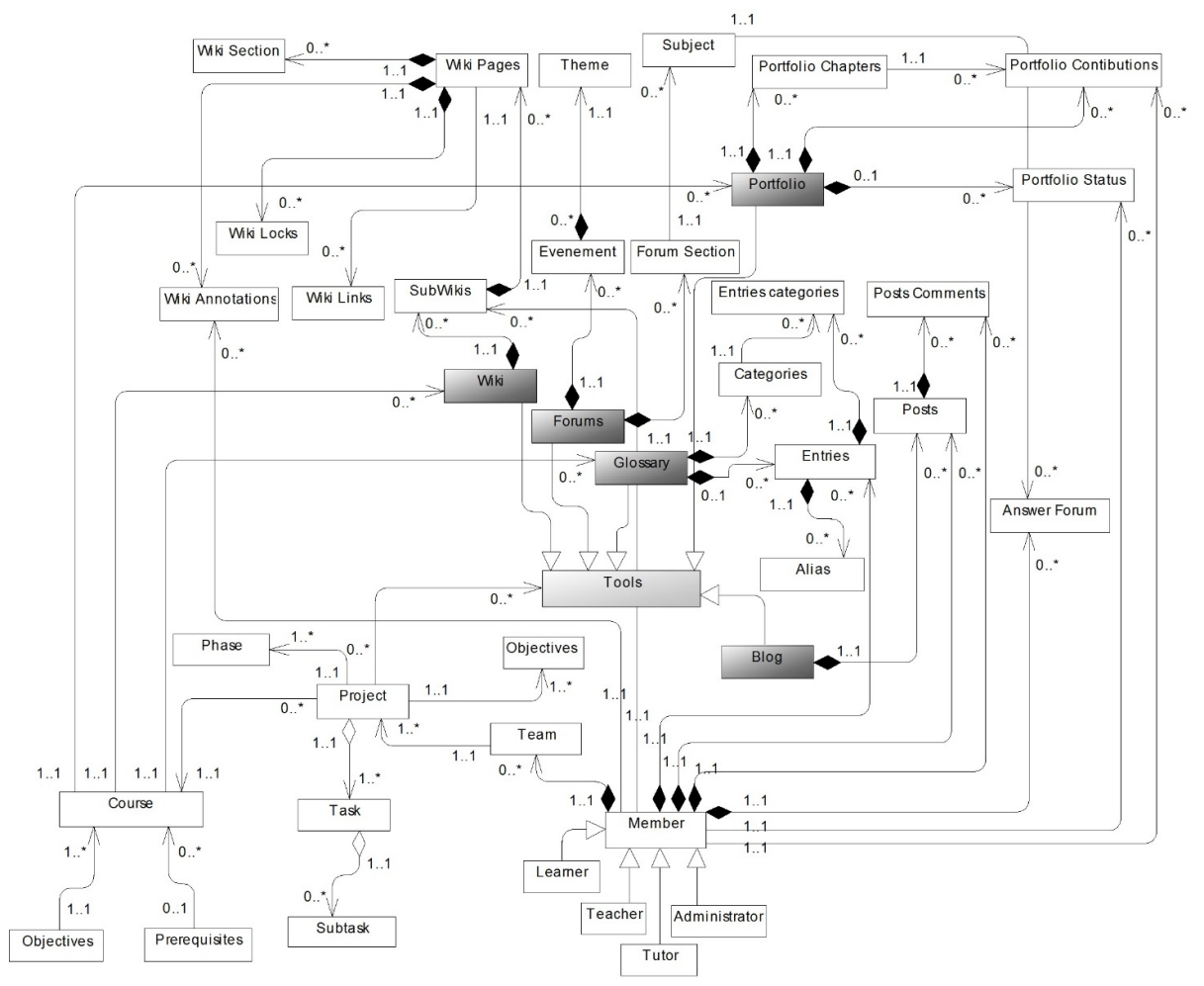

Fig. 4. Proposition of an conceptual meta-model of the collaboration space

\section{Conclusion and Perspectives}

In our work, we are on the way to the design and modeling generate a meta-Model content for collaboration space of Learning Management System compatible with 
IMS-LD. This design is based on active teachings learner-centered, and as an example of the pedagogy, we opted for theory as a basis for teaching this collaboration space of LMS, namely the social constructivism. The latter that allows us to reach a teaching object through the implementation of projects that are divided into tasks performed by students collaboratively or individually. To achieve a goal we need to reach the model validation step, which is one of the tasks to be performed in our future work; also, we seek a framework that will guide us better to start the development part.

\section{$7 \quad$ References}

[1] M. Ouadoud, M. Y. Chkouri, A. Nejjari, K. E. EL Kadiri, (2016) Studying and Analyzing the Evaluation Dimensions of ELearning Platforms Relying on a Software Engineering Approach. International Journal of Emerging Technologies in Learning (iJET). 2016, Vol. 11 Issue 1, p11-20. 10p. https://doi.org/10.3991/ijet.v11i01.4924

[2] M. Ouadoud, M. Y. Chkouri, A. Nejjari, and K. E. E. Kadiri, "Studying and comparing the free eLearning platforms," in 2016 4th IEEE International Colloquium on Information Science and Technology (CiSt), 2016, pp. 581-586. https://doi.org/10.11 $\underline{09 / C I S T .2016 .7804953}$

[3] M. Ouadoud, M. Y. Chkouri, A. Nejjari, and K. E. El Kadiri, "Exploring a Recommendation System of Free ELearning Platforms: Functional Architecture of the System," International Journal of Emerging Technologies in Learning (iJET), vol. 12, no 02, p. 219-226, Feb. 2017. https://doi.org/10.3991/ijet.v12i02.6381

[4] A. Lejeune, IMS Learning Design: Étude d'un langage de modélisation pédagogique, Revue Distances et Savoirs, volume 2.

[5] CEN/ISS WS/LT, Learning Technologies Workshop "Survey of Educational Modelling Languages (EMLs)".Version 1, September 2002.

[6] R. Koper, (2001). Modeling Units of Study from a Pedagogical Perspective, the pedagogical meta-model behind EML.

[7] D. Burgos, M. Arnaud, P. Neuhauser, and R. Koper, "IMS Learning Design," Association EPI, Décembre-2005.

[8] WAKE, Jo Dugstad. "Evaluating the Organising of a Collaborative Telelearning Scenario from an Instructor Perspective œ an Activity Theoretical Approach," PhD dissertation in computer science, Dept. of Information Science, University of Bergen, December, 2001. Thèse de doctorat.

[9] M. Ouadoud, A. Nejjari, M. Y. Chkouri, and K. E. El-Kadiri, "Learning Management System and the Underlying Learning Theories," in Innovations in Smart Cities and Applications, 2017, pp. 732-744. https://doi.org/10.1007/978-3-319-74500-8 67

[10] W. Doise and G. Mugny, Le développement social de l'intelligence (Vol. 1). Paris: Interéditions, 1981.

[11] M. Ouadoud, M. Y. Chkouri, and A. Nejjari, "Learning Management System and the Underlying Learning Theories: Towards a new Modeling of an LMS," International Journal of Information Science and Technology (iJIST), vol. 2, no. 1, pp. 25-33, Mar. 2018.

[12] F. Henri, "Rabardel, P. and Pastré, P. (éds) (2005). Modèles du sujet pour la conception. Toulouse," International Journal of ELearning \& Distance Education, Octares Éditions, 260 p., vol. 22, no. 1, pp. 101-106, Aug. 2007. 
[13] M. Sadiq and M. Talbi, "Modélisation des unités d'apprentissage sur des plates-formes de formation à distance," Association EPI, Mar-2010.

[14] E. Tonye, "Modeling a framework for open and distance learning in sub-Saharan African countries," frantice.net, numéro 2, December 2010.

[15] K. Chouchane, "Modélisation et réalisation d'une approche pour le m-learning," Magister en Informatique Option Système d'Informatique et de Communication (SIC) 2012, Université Hadj Lakhdar - Batna - Algérienne.

[16] S. Brunel, P. Girard, and M. Lamago, "Des plateformes pour enseigner à distance : vers une modélisation générale de leurs fonctions," in AIP Primeca 2015, La Plagne, France, 2015.

[17] B. née Dahmani Farida, "Modélisation basée ontologies pour l'apprentissage interactif Application à l'évaluation des connaissances de l'apprenant," $\mathrm{PhD}$ dissertation in computer science, Computer Science Department, Mouloud Mammeri University of Tizi-Ouzou, Algeria, 28 November, 2010.

[18] Alfanet project "CopperCore V 3.3," Nov-2008. CopperCore is one of the OUNL's contributions to the Alfanet project

[19] Bolton, "RELOAD Project: Editor," United Kingdom: The University of Bolton, The University of Strathclyde and JISC, 2005.

[20] F. El-Moudden, S. Aammou, and M. Khaldi. "A Tool to Generate a Collaborative Content Compatible with IMS-LD,” International Journal of Software and Web Sciences, 11(1), December 2014-February 2015, pp. 01-08.

[21] G. Dyke and K. Lund, "Implications d'un modèle de coopération pour la conception d'outils collaboratifs," Dec. 2006.

[22] C. Ferraris, Anne Lejeune, Laurence Vignollet, Jean-Pierre David. Modélisation de scénarios pédagogiques collaboratifs. 2005.

[23] F. El-Moudden, M. Khaldi, and S. Aammou, "Designing an IMS-LD Model for Collaborative Learning," IJACSA, vol. 1, no. 6, pp. 42-48.

[24] M. Chekour, M. Laafou, and R. Janati-Idrissi, "L'évolution des théories de l'apprentissage à l'ère du numérique," Association EPI, févr-2015.

[25] A. El Mhouti, A. Nasseh, and M. Erradi, "Les TIC au service d'un enseignementapprentissage socioconstructiviste," Association EPI, janv-2013.

[26] M. Ouadoud, M. Y. Chkouri, and A. Nejjari, "LeaderTICE: A Platforms Recommendation System Based on a Comparative and Evaluative Study of Free E-learning Platforms," International Journal of Online Engineering (iJOE), vol. 14, no. 01, pp. 132-161, Jan. 2018. https://doi.org/10.3991/ijoe.v14i01.7865

[27] M. Ouadoud, A. Nejjari, M. Y. Chkouri, and K. E. E. Kadiri, "Educational modeling of a learning management system," in 2017 International Conference on Electrical and Information Technologies (ICEIT), 2017, pp. 1-6. http://dx.doi.org/10.1109/EIT ech.2017.8255247

[28] M. U. Spence, "Graphic Design: Collaborative Processes. A course on collaboration, theory and practice" Art 325: Collaborative Processes. Fairbanks Hall, Oregon State University, Corvallis, Oregon. 2005.

[29] I. J. Martinez-Moyano, "Exploring the dynamics of collaboration in interorganizational settings," Creating a culture of collaboration: the International Association of Facilitators handbook, 2006.

[30] L. S. Vygotsky, Mind in Society: The Development of Higher Psychological Processes, Revised ed. edition. Cambridge: Harvard University Press, 1978. 
[31] P. Boulet, J.L. Dekeyser, C. Dumoulin, and P. Marquet. Mda for soc embeddeb systems design, intensive signal processing experiment. In SIVOESMDA workshop at UML 2003, San Francisco, October 2003.

[32] D. Thi-Lan-anh, G. Olivier, and S. Houari. Gestion de modèles : définitions, besoins et revue de littérature. In Premières Journées sur l'Ingénierie Dirigée par les Modèles, pages 115, Paris, France, 30 Juin- 1 Juillet 2005.

[33] A. Clave. D'UML à MDA en passant par les métas modèles. Technical report, La Lettre d'ADELI n 56, 2004.

[34] P. A. Caron, F. Hoogstoel, X. Le Pallec, and B. Warin. Construire des dispositifs sur la plateforme moodle - application de l'ingénierie bricoles. In MoodleMoot-2007, Castres, France, 14 - 15 Juin 2007.

[35] A. Canals, C. Le Camus, M. Feau, G. Jolly, V. Bonnafous, and P. Bazavan, "Une utilisation opérationnelle d'ATL: L'intégration de la transformation de modèles dans le projet TOPCASED," in Génie logiciel, 2005, pp. 21-26.

[36] J. Bézivin, G. Dupé, F. Jouault, G. Pitette, and J. Eddine Rougui. First experiments with the ATL model transformation language: Transforming xslt into xquery. In OOPSLA 2003 Workshop, Anaheim, California, 2003.

[37] OMG/RFP/QVT MOF 2.0 Query/Views/Transformations RFP. OMG, Object Management Group, 28 Oct. 2002.

[38] ATLAS group LINA and INRIA Nantes. Atlas transformation language. ATL user manual - version 0.7. Technical report, INRIA University of Nantes, February 2006.

[39] B. Combemale and S. Rougemaille. ATL - Atlas Transformation Language. Master 2 Recherche SLCP, module rtm edition, 2005.

[40] M. Ouadoud and M. Y. Chkouri, "Generate a Meta-Model Content for Disciplinary Information Space of Learning Management System Compatible with IMS-LD," in Proceedings of the 3rd International Conference on Smart City Applications, New York, NY, USA, 2018, p. 39:1-39:8. http://dx.doi.org/10.1145/3286606.3286816

[41] M. Ouadoud, T. Chafiq, and M. Y. Chkouri, "Designing an IMS-LD Model for Disciplinary Information Space of Learning Management System," in Proceedings of the 3rd International Conference on Smart City Applications, New York, NY, USA, 2018, p. 40:140:9. https://doi.org/10.1145/3286606.3286817

[42] M. Ouadoud, N. Rida, and M. Y. Chkouri, "Designing an IMS-LD Model for Collaboration Space of Learning Management System," in 2018 IEEE 5th International Con-gress on Information Science and Technology (CiSt), 2018, pp. 380-385. https://doi.org/10.1109/CIST.2018.8596588

\section{Authors}

Mohammed Ouadoud is a Ph.D. in Computer sciences, at the Laboratory of Informatics, Research Operational and Statistic Applied (LIROSA) at Faculty of Sciences, Abdelmalek Essaâdi University. In 2018, he completed his Ph.D. thesis in computer science at the faculty of science of Tetouan, Morocco. His dissertation research, focus on Modeling and Prototyping a Learning Management System Based on the IMD-LD and the Hybridization between Learning Theories. He has a Master degree in Multimedia Engineering of Instructional Design at the École Normale Supérieure of Martil, Morocco in 2013. His current research focuses on E-learning, Software Engineering, Man Machine Interface, Geomatics, Geotech and Bigdata. Mohammed 
Paper - Generate a Meta-Model Content for Collaboration Space of Learning Management...

Ouadoud is a reviewer in several International journals. (E-mail: mohammed.ouadoud@gmail.com).

Tarik Chafiq is a scientific collaborator at Hassan II University who is specialized in the research field of geometrics' such Geographical Information Systems (GIS) analyses and Spatial Data Infrastructures (SDI). He got his master degree and doctorate in geoinformatics. Furthermore, Microsoft certified him as an expert in C \# and HTML5. (E-mail: tarik.chafiq1@gmail.com).

Nouha Rida is currently a Ph.D. Student at Computer and Education Research Laboratory at Mohammadia School of Engineer, Mohammed V University, Morocco. She received her degree in engineering in computer science by "Ecole Nationale Superieur de Mine of Rabat". Her main research interests are related to the intelligent transportation system and road traffic optimization.

Mohamed Yassin Chkouri is with Laboratory of the Information System and Software Engineering (SIGL) at National School of Applied Sciences, Abdelmalek Essaadi University, Tetouan, Morocco. (E-mail: yassin.chkouri@gmail.com).

Article submitted 30 August 2018. Final acceptance 04 December 2018. Final version published as submitted by the author. 